\title{
Diversos
}

\section{O Doutorado}

Dr. João Arruda

Fala-se em extinguir o doutorado, e allegam-se em prol da idéa as mais futeis razões. Despesa excessiva è o primeiro argumento. Mas é muito parecido com o dos operarios ignorantes que julgam um vadio o homem de letras, do industrial bronco, que não vê no bacharel em Direito o defensor dos direitos dos proprietarios, e diz que basta haver na sociedade engenheiros e mecanicos, e dos mazorros, em geral, que não conhecem a influencia do factor intellectual sobre a economia social e a do particular. Oppozse tambem a difficuldade de encontrar uma hora propria para esse serviço, que importa em riqueza para a nação, visto como não são os bens materiaes que na verdade a constituem. A possibilidade de os produzir e de os manter em bem ordenada distribuição economica é que realmente gera o conforto para o povo, o bem estar para o maior numero. E' difficil encontrar uma hora propicia para os altos estudos, e trabalhos extraordinarios. Todos os que fazem parte do Tribunal Eleitoral (serviço penoso e mal remunerado, ou peior do que si o não fosse) sabem a difficuldade que seus membros encontraram em acudir a esse penoso dever civico após dias de duro labor. Os advogados que compõem o conselho da Ordem lembram. se da lucta para acertarem em um momento de lazer em que se occupassem dos interesses da classe. E são 5 os membros do Tribunal Eleitoral, e 21 os da Ordem. Figure-se o que será harmonizar, para o curso do doutorado, interesses de 100 advogados, sobrecarregados de trabalhos no fôro. Quando eu me achava na regencia de uma das cadeiras do curso, propuz fossem as aulas dadas á noite. Nova difficuldade: allegou o director não haver verba para luz e para funccionarios em hora extraordinaria.

Seja porém com que sacrificio fôr, o doutorado deverá ser mantido ou cumpre ser extincta a Universidade. E' esta destinada a 
evitar as vistas parciaes, daquelles que só conhecem o pouco indispensavel á vida forense ou administrativa.

Quem sahe do curso do bacharelado pensa que o mundo se cifra no que está na legislação patria. Comprehendeu bem esta missão Bugnet, quando affirmou não saber o Direito Civil, e só ensinar o Codigo Napoleão (Gény, Methodo de Interpretação, n. 13). Era, mais ou menos, o modo de pensar de Robespierre (Gény, n. 45). Um jurista nestas condições pensa que Direito é o que foi consagrado em lei e na jurisprudencia do momento historico actual em nosso paiz, como sendo a consciencia do justo e do injusto:

"Et juge ì son enclos, bornant son horizon,

"Que le monde finit où finit sa maison".

Mas o proprio advogado práctico não pode dispensar um golpe de vista mais vasto, uma vez que a vida forense é um kaleidoscopo, e que nem sempre é possivel, na caça ao caso, encontrar um julgado dos tribunaes proveitoso á especie que o interessa. Não direi, com Cogliolo, que é uma felicidade que os tribunaes não tenham resolvido todos os casos, porque assim estão os advogados obrigados a um esforco, mas sim que, si quizessem estes servir conscienciosamente os clientes deveriam, nos muitos casos de que não cogitaram os juizes, fazer estudos superiores aos de busca de um aresto favoravel. Ainda ha pouco se me deparou em um artigo de Ralph Dox, advogaido nos auditorios de Buffalo, America do Norte, a terra dos arestos, no Case and Comment, em que o jurista mostra a necessidade de valerem-se do Direito Romano os dedicados á vida forense: "Help from Rome".

No pouco espaço de que disponho, seja-me permittido apontar dois exemplos da impossibilidade de interpretação do nosso Codigo Civil sem valer-se o jurisconsulto do recurso de vista mais geral, semelhantes á de quem sobe a um ponto elevado para descortinar mais largo horizonte. Poderá o locador de um predio augmentar, sem limites, o aluguel, em face do disposto no art. 1196 do Codigo Civil? Ou estará sujeito á limitação do art. 920? Vacillam os julgados. Poderá o interprete responder, a menos de querer fazer adivinhações mais ou menos felizes, no dizer de Cogliolo, sem conhecimento das condições economicas do paiz, da situação de inquilinos e proprietarios, da abundancia ou falta de predios de aluguel, para saber si ha, ou não, abuso do proprietario ou capitalista? Note-se que, alem do mais, variam muito as condições sociaes quanto ás habitações. 0 problema do inquilinato abalou profundamente os jurisconsultos após a grande guerra. 
Outra questão em que têm variado os tribunaes é a relativa á interpretação do art. 570 do Codigo Civil. Quando ha uma gleba sobre a qual não puderam os condominos apurar titulos de propriedade, ou é duvidoso qual delles tem sobre ella direito, deve ser repartida proporcionalmente. Será na proporção dos quinhões, como antigamente decidia o nosso Tribunal (Rev. dos Tribs. 64/250 e 71/512), ou pelo meio, em partes iguaes, como julga hoje (Rev. dos Tribs. 92/407), e é ensinado por Clovis nos commentarios a este artigo? Pela 1. ${ }^{a}$ solução em pleito entre um proprietario de mil hectares de terra e o de um unico, será este aquinhoado em um millesimo do terreno litigioso!... E' a protecção á grande propriedade, das leis portuguezas, é manter-se o ponto de vista dos reis portuguezes, que julgavam ser sua grandeza e da aristocracia lusitana proporcional ao tamanho das propriedades agricolas (L. de 9 de Julho de 1773 , preambulo). O $20^{\circ}$ modo de entender nossa lei é protector da pequena propriedade, pela qual se bateu ardentemente Stuart Mill. Como pois, sem conhecimentos economicos, sem estudos da grande sciencia de Adam Smith, poderá argumentar o práctico, e será dado ao juiz sentenciar com acerto?

A mesma alta cultura, o mesmo conhecimento das condições economicas do paiz, deve ter quem quizer interpretar o art. 928 do Codigo Civil, para dizer si esse favor outorgado pela lei ao devedor pode por este ser renunciado, dúvida que se apresenta quasi sempre, no fôro, em casos de locação de predios urbanos, e que tem sido solvida de modo vario pelos nossos tribunaes.

Passo ao Direito Publico. Sem duvida pode o professor de Direito Publico dizer algo verdadeiro sobre os assumptos de ordem publica, mas com muita cautela, porque os noveis, com o cerebro prenhe de preconceitos, não estão em condições de bachareis do curso do doutorado, aptos a receberem taes verdades. Não deixa de ter seu fundamento a divisão de estudos em isotericos e exotericos. Mas, de fóra parte ésta difficuldade, como explicar a principiantes o que é uma Constituição, e como a idéa da lei fundamental variou em diversos tempos e em varios povos? Da Magna Carta, e mesmo do Decalogo ou das 12 Taboas até nossos dias, quanta diversidade no modo de entender o que deve encontrar-se em uma Constituição! (Já ouço clamar que o Decalogo e as 12 Taboas não são constituições, como ouvi ser erro de Huxley dizer que a Biblia é democratica: não respondo por amôr á brevidade). Entretanto, em nossa constituinte, recentissimamente, viram-se muitos deputados que, em um dogmatismo lastimavelmente revelador da mais crassa ignorancia, pretendiam plasmar a nova Constituição nos moldes da que conheciam de ouvido ou de leitura, da de $1891 ! \ldots$ Não fossem os trabalhos (em- 
bora pouco conhecidos no Brasil) de Mirkine Guetzevitch, dando noticia da mudança por que passaram as ideas sobre os codigos fundamentaes nestes ultimos annos, e teriam sido dictas muitas outras heresias no congresso constituinte, que tanto dinheiro custou á patria brasileira...

$\mathrm{Na}$ administração, ainda é mais accentuada a incapacidade dos governantes. Cada vez que o Estado se afoita em uma medida, por muito bôa que seja, como o seria a economia dirigida, é certo que a vae applicar em condições de molde a desmoralizal-a. A procura de mercados para os productos que se dizem em excesso em um paiz só poderia ser levada á practica por gente conhecedora do commercio mundial. Este ramo de estudos economicos, segundo creio pelos livros que conheço, só foi cultivado na Inglaterra e em pequenissima escala em França. (Mac Culloch, Yves Guyot etc.).

Mas cumpre-me pôr termo a éstas linhas, em que tento salvar uma instituição indispensavel á vida universitaria, e pela qual tanto fez o illustre mestre o desembargador Masagão rem sua nova e optima regulamentação da Faculdade de Direito, e consequentemente passo á Politica, quer interna, quer externa. Já não é possivel seguir o conselho de Franklin, quando sustentou deverem os Estados ser muito relacionados economicamente, sem terem todavia nenhuma interferencia official, e não manterem relações officiaes sinão em casos excepcionalissimos: guerra pois á diplomaicia. Ainda que, após os trabalhos de Ralston e o procedimento dos diplomatas Bismarck e Berchtold, estejam todos convencidos de que os diplomatas nada mais fazem do que intrigar, e armar guerras para proveito de certos exploradores dos males humanos, o que é fóra de dúvida é que, com o radio, o telegrapho internacional, a rapidez das communicações aéreas e os aperfeiçoados meios de transporte de homens, de mercadonias e mesmo do pensamento, impossivel é absterem-se os povos de manterem relações officiaes constantes.

Como porém dirigil-as, como apreciar o modo de proceder dos varios Estados? Um só exemplo darei, e será tirado da revolta da armada em 1893. Só conheço dois sobreviventes dessa tremenda hecatombe: falo sine ira et studio, embora muito ligado a esses elementos. Causou profunda sensação o modo por que Floriano se referiu, em mensagem ao Ciongresso aos bravos que lhe resistiram durante longos mezes em epica lucta.

No entanto, quem conhecer psychologi'a, quem estudar o caso pelo aspecto philosophico, comprehenderá que assim agiu o dictador obnubilado pela colera, colera que só poderia ser sopitada por uma cultura, que o marechal se gabava de não possuir. Causou pasmo a attitude dos Estados Unidos e particularmente do almirante Benheim, ao malsinar os heroes de 93 de covardia, estando elle escondido 
isolado no meio da bahia Guanabara de medo de febre amarella. Quem conhece o desprezo profundo dos anglo-saxões para com os latinos, quem sabe que elles se julgam de raça superior, seguramente entenderá que foi excessivo Eduardo Prado (Illusão Americana) na violenta repulsa que lhes fez.

Todos se recordam de que, estando aqui Bryce, ao tempo da revolta João Candido, narrou, mais tarde, em sua obra sobre a America Latina, o facto adulterado, e procurou cobrir-nos de ridiculo. Tendo tambem assístido no Rio a uma festa popular, inferiu que os brasileiros são apaixonados pelos foguetes!... Direi de passo que ha nisto um fundo de verdade, mas que cumpre additar estar eu certo de que, quando o anglo saxonio, o homem da taciturna cidade de Londres, inhabitavel terra do plumbeo nevoeiro, viu os foguetes, em silvo alegrissimo, subir, sob uma atmosphera limpida, em direcção a um ceu de anil, e dar nas alturas tres estalinhos sonóros, como que querendo levar a alegria communicativa dos cariocas á côrte celeste, sentiu seguramente inveja da felicidade destes homens semi nús e resumando suor e felicidade. Grande indignação houve por parte de todos os bons brasileiros dotados de nobres sentimentos contra o procedimento do Conde de Paraty, mas ella seria attenuada si comprehendessem o que é o representante do governo de uma nação fraca perante um paiz de quem deseja captar as bôas graças: não recuava o diplomata deante da mais vil das covardias, qual a de entregar a Floriano enfuriado os nossos bravos marinheiros, para que este os mandasse matar. Não representava Paraty a generosa nação portugueza: ésta manifestou-se pelo lance nobilissimo de Castilho. Tudo isto precisa ser estudado por quem conhece a psychologia dos povos (sciencia em formação) e a psychologia dos diplomatas profissionaes, hoje tão pouco recommendaveis e mesmo em completo descredito.

Examinada a occurrencia, como o foi pelo aspecto dos preconceitos do momento, por gente sem preparo do nosso congresso legislativo, deu em resultado a injusta condemnação do acto do grande portuguez de nome immorredouro, que foi Castilho.

Mas como estudar casos destes perante alumnos principiantes tão imbuidos em preconceitos, discipulos que chegam a julgar seus mestres semeadores de doutrinas subversivas? Mantenha-se o doutorado, onde intelligencias amadurecidas poderão comprehender o Direito em toda a a sua grandeza, em suas linhas architectonicas deslumbrantes. Façam-se para tal todos os sacrificios, e só assim será salvo este espirito universitario com que terão nossos intellectuaes vistas largas, e de conjuncto nas relações intrincadissimas da vida social.

N. da R.: - Respeitada a ortografia do autor. 